\title{
Atomic structure of cobalt-oxide nanoparticles active in light- driven catalysis of water oxidation
}

Marcel Risch ${ }^{\mathrm{a}}$, Denys Shevchenko ${ }^{\mathrm{b}}$, Magnus F. Anderlund ${ }^{\mathrm{b}}$, Stenbjörn Styring ${ }^{\mathrm{b}}$ Jonathan Heidkamp $^{\mathrm{a}}$, Kathrin M. Lange ${ }^{\mathrm{c}}$, Anders Thapper ${ }^{\mathrm{b}}$, Ivelina Zaharieva ${ }^{\mathrm{a}^{*}}$

${ }^{\mathrm{a}}$ Freie Universität Berlin, Institut für Experimentalphysik, Arnimallee 14, 14195 Berlin, Germany.

${ }^{\mathrm{b}}$ Department of Photochemistry and Molecular Science, Uppsala University, P.O.Box 523, S75120 Uppsala, Sweden.

${ }^{c}$ Helmholtz-Zentrum Berlin für Materialien und Energie, Albert-Einstein-Str. 15, 12489 Berlin, Germany.

*Correspondence to:

Dr. Ivelina Zaharieva, Freie Universität Berlin, Institut für Experimentalphysik, Arnimallee 14, 14195 Berlin, Germany; Fax +49 30838 56299, Phone +49 30838 56167, Email: ivelina.zaharieva@fu-berlin.de

\begin{abstract}
Abbreviations:
CoCat, electrodeposited Co oxide catalyst for water oxidation; EXAFS, extended X-ray absorption fine structure; FT, Fourier transformation; M2P, methylenediphosphonate; PSII, photosystem II; XANES, X-ray absorption near-edge structure; XAS, X-ray absorption spectroscopy
\end{abstract}




\begin{abstract}
The atomic structure of water-oxidizing nanoparticles $(10-60 \mathrm{~nm})$ formed from cobalt(II) salts and methylenediphosphonate (M2P) is investigated. These amorphous nanoparticles are of high interest for production of solar fuels. They facilitate water oxidation in a directly lightdriven process using $\left[\mathrm{Ru}(\mathrm{bpy})_{3}\right]^{2+}\left(\mathrm{bpy}=2,2^{\prime}\right.$-bipyridine $)$ as a photosensitizer and persulfate $\left(\mathrm{S}_{2} \mathrm{O}_{8}{ }^{2-}\right)$ as an electron acceptor. By X-ray absorption spectroscopy (XAS) at the cobalt $K$ edge, cobalt $L$-edge and oxygen $K$-edge, we investigate the light-driven transition from the $\mathrm{Co}^{\mathrm{II}} / \mathrm{M} 2 \mathrm{P}$ precursor to the active catalyst, which is a layered cobalt(III) oxide with structural similarities to water-oxidizing electrocatalysts. The M2P ligand likely binds at the periphery of the nanoparticles, preventing their further agglomeration during the catalytic reaction. This system opens a possibility to link the catalytically active nanoparticles via a covalent bridge to a photosensitizer and build an artificial photosynthetic system for direct utilization of solar energy for fuel production without production of electricity as an intermediate step.

This article is part of a Special Issue entitled: Photosynthetic and Biomimetic Hydrogen Production.
\end{abstract}

Keywords: artificial photosynthesis, photocatalysis, solar fuels, water oxidation, X-ray absorption spectroscopy 


\section{Introduction}

Our society is heavily dependent on fossil fuels needed for operating combustion engines in transportation and production of electrical energy. This has led to an increased level of carbon dioxide, a greenhouse gas, in the atmosphere which ultimately might cause drastic changes in the climate on Earth [1-3]. To decrease our dependence on fossil fuels, scientists are searching for new routes towards production of renewable energy. Molecular hydrogen is an attractive fuel option, as it burns to water without carbon dioxide formation. The only viable starting material for the sustainable large-scale production of hydrogen is water.

The production of hydrogen from water can be broken down into two steps. Firstly, the oxidation of water to form oxygen, protons, and electrons and secondly, the reduction of protons to form hydrogen according to Eq. 1 and 2, respectively.

$$
\begin{aligned}
& 2 \mathrm{H}_{2} \mathrm{O} \rightarrow \mathrm{O}_{2}+4 \mathrm{H}^{+}+4 \mathrm{e}^{-} \\
& 4 \mathrm{H}^{+}+4 \mathrm{e}^{-} \rightarrow 2 \mathrm{H}_{2}
\end{aligned}
$$

In comparison to hydrogen formation by proton reduction (Eq. 2), the four-electron/fourproton chemistry of water oxidation (Eq. 1) is clearly more thermodynamically demanding [45].

Nature can catalyze both reactions with exceptionally high efficiency. Water oxidation is carried out by Photosystem II (PSII), which is a highly conserved protein-cofactor complex found in plants, algae, and cyanobacteria [6-8]. Water is split into oxygen, protons, and electrons at a $\mathrm{Mn}_{4} \mathrm{O}_{5} \mathrm{Ca}$ cluster, which is bound to the PSII protein complex [9-14].

Many attempts to synthesize artificial catalysts have involved manganese oxides or multinuclear manganese complexes with intricate ligand systems [15-32]. Some of these exhibit water-oxidation activity, but at comparatively low turnover frequencies and numbers [1517,20-22,24-29]. Ruthenium and iridium based catalysts show a better performance, but the metals are scarce and expensive [33-39], which is a serious drawback if the catalysts are to be used on a large scale. In this case the use of earth-abundant elements is clearly mandatory. Much research has been devoted to cobalt-oxo materials as very promising candidates for water oxidation catalysts [40-46]. In particular, electrodeposited cobalt oxide films (herein called CoCat) have been shown to be efficient in electrochemical water oxidation [41,47]. Cobalt oxides and molecular complexes have been utilized as catalysts for light-driven water oxidation in a solution containing suitable photosensitizers [33,42,46,48-53]. Cobalt oxides 
were also deposited and operated on photoanodes, such as $\alpha-\mathrm{Fe}_{2} \mathrm{O}_{3}$ [54-58], $\mathrm{ZnO}$ [59], $\mathrm{WO}_{3}$ [60], $\mathrm{W}: \mathrm{BiVO}_{4}[61]$, and on Si-based solar cells [62-64].

Connecting the water oxidation catalyst to a photovoltaic cell is an indirect method where a potential difference of at least $0.8 \mathrm{~V}$ at $\mathrm{pH} 7$ must be generated to facilitate the water oxidation reaction. As an alternative and, in our eyes, more desirable approach, solar energy can be employed to generate a chemical oxidant which directly drives the water splitting reaction. The advantage of a molecular oxidant is that it can be tailored to the specific needs of a given catalytic system. The direct covalent coupling of a photosensitizer to a cobalt oxide nanoparticle however had not been achieved yet.

In a previous work, cobalt-based nanoparticles were formed in-situ from cobalt and methylenediphosphonate, $\mathrm{M}^{2} \mathrm{P}^{1}$, under oxidizing conditions in a phosphate buffer ( $\left.\mathrm{pH} 7\right)$. These particles work as water oxidation catalysts in a direct light-driven process using $\left[\mathrm{Ru}(\text { bpy })_{3}\right]^{2+}\left(\right.$ bpy $=2,2^{\prime}$-bipyridine $)$ as a photosensitizer and persulfate $\left(\mathrm{S}_{2} \mathrm{O}_{8}{ }^{2-}\right)$ as an electron acceptor [46]. The nanoparticles are limited in size to $10-60 \mathrm{~nm}$ radius in the presence of M2P. Under illumination, the nanoparticles could catalyze the production of $\sim 20$ dioxygen molecules per cobalt atom at a rate of $\sim 0.2 \mathrm{~mol} \mathrm{O}_{2} \mathrm{~s}^{-1}(\mathrm{~mol} \mathrm{Co})^{-1}$. Interestingly, when excluding the M2P ligand, the same activity was determined but the particles grew to a size of at least one micrometer.

The small M2P molecules offer a possibility to link the cobalt-based nanoparticles via a covalent bridge to a photosensitizer and utilize the solar energy for fuel production directly, without creation of an electric potential at a conducting electrode as an intermediate step. Such a direct conversion could increase the quantum efficiency pronouncedly by minimizing recombination losses after light excitation. Therefore, atomic structure and arrangement of the constituents of the nanoparticles (cobalt ions, M2P ligand, water-derived ligands) are of high interests. As the Co/M2P nanoparticles are amorphous and cannot be studied by X-ray powder diffraction, we employ X-ray absorption spectroscopy, XAS, at three different absorption edges (cobalt $K$-edge, cobalt $L$-edge and oxygen $K$-edge). This comprehensive approach is relatively rarely used [65-66] because optimized experimental setups for soft Xrays (oxygen $K$-edge and cobalt $L$-edges) and hard X-rays (cobalt $K$-edge) are required. Combining the complementary structural information obtained by the measurements in the different energy domains, herein we derive a model of the atomic structure of the cobalt oxide nanoparticles and assess the structural role of the M2P ligand. 


\section{Material and methods}

$\mathrm{H}_{4} \mathrm{M} 2 \mathrm{P}$ was prepared as described in ref [67]. [ $\left.\mathrm{Ru}^{\mathrm{II}}(\mathrm{bpy})_{3}\right]\left(\mathrm{ClO}_{4}\right)_{2}$ was prepared by anion exchange from $\left[\mathrm{Ru}^{\mathrm{II}}(\mathrm{bpy})_{3}\right] \mathrm{Cl}_{2}$ (Aldrich) and recrystallized from $\mathrm{MeCN} / \mathrm{Et}_{2} \mathrm{O} \cdot \mathrm{Co}(\mathrm{Ac})_{2} \cdot 4 \mathrm{H}_{2} \mathrm{O}$ (Aldrich), $\mathrm{Co}\left(\mathrm{ClO}_{4}\right)_{2} \cdot 6 \mathrm{H}_{2} \mathrm{O}$ (Aldrich), $\mathrm{Co}\left(\mathrm{OH}_{2}\right)_{6}\left(\mathrm{NO}_{3}\right)_{2}$ (Aldrich), $\mathrm{Na}_{2} \mathrm{~S}_{2} \mathrm{O}_{8}$ (Aldrich) $\mathrm{KH}_{2} \mathrm{PO}_{4}$ (AppliChem), $\mathrm{K}_{2} \mathrm{HPO}_{4}$ (AppliChem), $\mathrm{LiCo}^{\mathrm{III}} \mathrm{O}_{2}$ (Aldrich) and $\mathrm{Co}_{3}{ }_{3}\left(\mathrm{PO}_{4}\right)_{2}(\mathrm{ABCR})$ were bought and used as received.

\subsection{Preparation of $\mathrm{Co} / \mathrm{M} 2 \mathrm{P}$ in solution}

Two samples $(1 \mathrm{ml})$ containing $\mathrm{Co}\left(\mathrm{ClO}_{4}\right)_{2} \cdot 6 \mathrm{H}_{2} \mathrm{O}(1.8 \mathrm{mM})$ and $\mathrm{H}_{4} \mathrm{M} 2 \mathrm{P}(2.5 \mathrm{mM})$ in $50 \mathrm{mM}$ $\mathrm{KH}_{2} \mathrm{PO}_{4} / \mathrm{K}_{2} \mathrm{HPO}_{4}$ buffer $\left(\mathrm{KP}_{\mathrm{i}}\right)$ with $\mathrm{pH} 7$, were prepared in the dark. To each sample, $\left[\mathrm{Ru}(\mathrm{bpy})_{3}\right]\left(\mathrm{ClO}_{4}\right)_{2}(0.77 \mathrm{mg}, 1 \mu \mathrm{mol})$ and $\mathrm{Na}_{2} \mathrm{~S}_{2} \mathrm{O}_{8}(5.9 \mathrm{mg}, 25 \mu \mathrm{mol})$ were added as powders. The solutions were ultrasonicated for 2 minutes to dissolve all powders. One sample was transferred to a cell equipped with a Clark electrode that was kept at $20^{\circ} \mathrm{C}$ and deaerated using a flow of argon. The cell was sealed using a rubber stopper and illuminated for 5 min (470 nm LEDs, $\sim 580 \mu \mathrm{E})$ after which an aliquot was withdrawn with a syringe. This aliquot (oxidized Co/M2P) was filled into a $1.5 \mathrm{~mm}$ thick plastic frame with $5 \mathrm{~mm} \times 10 \mathrm{~mm}$ opening secured with $25 \mu \mathrm{m}$ thick Kapton ${ }^{\circledR}$ foil. An aliquot from the non-illuminated sample (Co/M2P precursor) was filled into a second frame. The sample cells were immediately frozen in liquid nitrogen where they were kept until the X-ray absorption measurements.

\subsection{Preparation of $\mathrm{Co} / \mathrm{M} 2 \mathrm{P}$ as dried powders}

\subsubsection{Preparation of $\mathrm{Co} / \mathrm{M} 2 \mathrm{P}$ precursor}

Two $\mathrm{ml}$ of a $0.10 \mathrm{M}$ hot aqueous solution $\mathrm{Co}(\mathrm{Ac})_{2} \cdot 4 \mathrm{H}_{2} \mathrm{O}(51.5 \mathrm{mg})$ was mixed with $2 \mathrm{ml}$ of $0.14 \mathrm{M}$ aqueous solution of $\mathrm{H}_{4} \mathrm{M} 2 \mathrm{P}(50.5 \mathrm{mg})$. The mixture equilibrated overnight and the resulting pink precipitate was collected using centrifugation (5 min, $14000 \mathrm{rpm}$; yield $\sim 30 \mathrm{mg}$.).

\subsubsection{Preparation of oxidized Co/M2P}

$50 \mathrm{ml}$ of $8.0 \mathrm{mM}$ aqueous solution of $\mathrm{Co}(\mathrm{Ac})_{2} \cdot 4 \mathrm{H}_{2} \mathrm{O}(100 \mathrm{mg}), 50 \mathrm{ml}$ of $11.2 \mathrm{mM}$ aqueous solution of $\mathrm{H}_{4} \mathrm{M} 2 \mathrm{P}(99 \mathrm{mg}), 50 \mathrm{ml}$ of $40 \mathrm{mM}$ aqueous solution of $\mathrm{Na}_{2} \mathrm{~S}_{2} \mathrm{O}_{8}(476 \mathrm{mg})$ and $50 \mathrm{ml}$ of deionized water were mixed together and then added to $200 \mathrm{ml}$ of $0.1 \mathrm{M}$ aqueous acetate buffer (pH 6.2; HAc/KAc) containing $100 \mathrm{mg}$ of $\left[\mathrm{Ru}(\mathrm{bpy})_{3}\right]\left(\mathrm{ClO}_{4}\right)_{2}$. The obtained solution was stirred in an Erlenmeyer flask with a volume of $1 \mathrm{~L}$ and illuminated for $10 \mathrm{~min}$ with a 150 Watt tungsten lamp. The color of the solution turned from red-orange to dark- 
green. After illumination $400 \mathrm{ml}$ of acetone was added to the reaction mixture. The resulting suspension was transferred into sixteen $50 \mathrm{ml}$ polyethylene tubes and centrifuged for $5 \mathrm{~min}$ at $5000 \mathrm{rpm}$. The supernatant was removed and the pellets were transferred into one tube and ultrasonicated with $50 \mathrm{ml}$ of acetone. Centrifugation (5 min, $5000 \mathrm{rpm}$ ) of the suspension in acetone gave a dark-green material. The isolated material (yield $\sim 55 \mathrm{mg}$ ) was dried in air before X-ray spectroscopic measurements and elemental analysis. Elemental analysis $(\mathrm{C}, \mathrm{H}$, $\mathrm{P}, \mathrm{Co}$ ) was performed by Analytische Laboratorien $\mathrm{GmbH}$, Lindlar, Germany (Co, 31.73\%; C, $4.16 \% ; \mathrm{P}, 8.76 \% ; \mathrm{H}, 2.39 \%)$.

\subsection{Preparation of electrodeposited CoCat}

The CoCat film was formed by anodic electrodeposition in $0.1 \mathrm{M} \mathrm{KP}_{\mathrm{i}}, \mathrm{pH}$. The electrochemical cell consisted of a custom made glass vessel, a glassy carbon plate $(1 \times$ $2.5 \mathrm{~cm}$ ) as working electrode, a Pt mesh as a counter electrode and an $\mathrm{Hg} / \mathrm{Hg}_{2} \mathrm{SO}_{4}$ (saturated) reference electrode (650 mV vs. NHE). For deposition, an appropriate amount of $\mathrm{Co}\left(\mathrm{OH}_{2}\right)_{6}\left(\mathrm{NO}_{3}\right)_{2}$ was added so that the final concentration of $\mathrm{Co}^{2+}$ ions was $0.5 \mathrm{mM}$. The CoCat film was deposited on the working electrode for $10 \mathrm{~min}$ at constant potential of $1.35 \mathrm{~V}$. After the deposition, the CoCat was stored in a desiccator under low vacuum. Before any of the films were loaded into the sample chamber for synchrotron measurements, they were inserted into cobalt-free $\mathrm{KP}_{\mathrm{i}}, \mathrm{pH} 7$, and $1.35 \mathrm{~V}$ (NHE) was applied for $2 \mathrm{~min}$.

\subsection{XAS measurements}

The XAS measurements were performed at the Helmholtz-Zentrum Berlin für Materialien und Energie (formerly BESSY II, Berlin). The measurements at the cobalt $K$-edge were acquired at the KMC-1 bending-magnet beamline at $20 \mathrm{~K}$ in a cryostat (Oxford-Danfysik) with a liquid-helium flow system. The XAS measurements at the oxygen $K$-edge and cobalt $L_{2,3}$-edges were carried out at the U41-PGM undulator Beamline at room temperature using the Liquidrom endstation [68]. Further details are given in the Supplementary Material.

\section{Results}

The ligand M2P forms a complex with $\mathrm{Co}^{2+}(K=12.03)$ [69]. This complex is the Co/M2P precursor. In the experiments presented here the amount of $\mathrm{Co}^{2+}$ that is not bound to $\mathrm{M} 2 \mathrm{P}$ (for example as $\left.\mathrm{Co}_{3}\left(\mathrm{PO}_{4}\right)_{2}\right)$ is kept at a very low level by adding the M2P in a 1.4 times excess [46]. The oxidation process is light-driven by using a photosensitizer and an electron acceptor. 
When the illumination starts, an excited state, $\left[\mathrm{Ru}^{\mathrm{II}}(\mathrm{bpy})_{3}\right]^{*^{2+}}$, forms. This state can pass one electron to the electron acceptor resulting in formation of $\left[\mathrm{Ru}{ }^{\mathrm{III}}(\mathrm{bpy})_{3}\right]^{3+}$, which is a powerful oxidation agent $\left(\mathrm{E}_{0} \approx+1.3 \mathrm{~V}\right)$. $\left[\mathrm{Ru}^{\mathrm{III}}(\mathrm{bpy})_{3}\right]^{3+}$ then oxidizes the $\mathrm{Co} / \mathrm{M} 2 \mathrm{P}$ precursor and $\mathrm{Co} / \mathrm{M} 2 \mathrm{P}$ nanoparticles forms that catalyze the oxidation of water. The activity of the $\mathrm{Co} / \mathrm{M} 2 \mathrm{P}$ nanoparticles, both before and after isolation as a powder, was verified by a Clark electrode (for details see Supplementary Material). To elucidate the structure of the Co/M2P complex in the precursor (dark) state and the light induced structural changes in the Co/M2P complex, which lead to formation of an active water oxidizing catalyst, we employed X-ray absorption spectroscopy at the cobalt $K$ - and $L$-edges and at the oxygen $K$-edge.

\subsection{X-ray absorption spectroscopy at the cobalt $K$-edge}

\subsubsection{XANES spectra}

In $K$-edge XAS, the sample is illuminated with X-rays of sufficient energy to excite an electron from the inner most shell of the probed atom ( $1 s$ shell). In the case of the first row transition metals as $\mathrm{Co}$, the transition is from the $1 s$ shell to the partially unoccupied $3 d$ levels (this transition result in the so-called pre-edge in the spectrum), and-for further increase of the energy - to the continuum. As the $1 s-3 d$ electron transition is dipole forbidden, the preedge intensity of the transition metal complexes is often very low. Increased pre-edge intensity is anticipated only in the case of strong mixing of the metal $3 d$ orbitals with ligand orbitals of $p$-character. This may occur in the case of very short oxo-bonds (for example in permanganates [70]) or by deviation from octahedral symmetry [71]. For Co, the $1 s-3 d$ electron transition gives rise to the absorption around $7710 \mathrm{eV}$ and the low intensity of the pre-edge corresponds to the octahedral coordination of the Co ions in the $\mathrm{Co}_{3}{ }_{3}\left(\mathrm{PO}_{4}\right)_{2}$ and $\mathrm{LiCo}^{\mathrm{III}} \mathrm{O}_{2}$ references, as well as in the CoCat and the $\mathrm{Co} / \mathrm{M} 2 \mathrm{P}$ complexes. The octahedral coordination of the $\mathrm{Co} / \mathrm{M} 2 \mathrm{P}$ complexes was confirmed also by the EXAFS measurements (see below).

A major increase of the absorption is observed when the incident X-ray energy increases and the $1 s$ electron is excited to the higher unoccupied orbitals ( $4 p$ and higher). The position of this sharp increase of the absorption (main absorption edge) shifts to higher energy with an increase of the formal oxidation state of the probed element [72-73]. Comparison to the reference compounds with known oxidation state allows determination of the metal oxidation state in unknown compounds [70,74]. As seen from Fig. 1, binding of M2P ligand to the Co ${ }^{\mathrm{II}}$ 
does not change the oxidation state of $\mathrm{Co}^{\mathrm{II}}$ ions, as the edge position stays the same as in the reference compound $\mathrm{Co}_{3}{ }_{3}\left(\mathrm{PO}_{4}\right)_{2}$ (Fig. 1).

After illumination the $\mathrm{Co} / \mathrm{M} 2 \mathrm{P}$ system is oxidized and the $\mathrm{Co} / \mathrm{M} 2 \mathrm{P}$ edge position shifts to the position of the $\mathrm{LiCo}^{\mathrm{III}} \mathrm{O}_{2}$ reference compound. This is paralleled by structural changes, mirrored in the change of the shape of the absorption edge. Visual inspection shows close similarity between the light-oxidized Co/M2P and the electrodeposited CoCat [75-76], but detailed information about structural changes can be deduced only from the oscillations after the absorption edge (EXAFS region). 


\subsubsection{EXAFS spectra}

The X-ray absorption above the edge (EXAFS region) is modified by the atoms, surrounding the Co absorber. In the Fourier transforms, FT, of EXAFS oscillations (Fig. 2), each peak corresponds to atoms surrounding the X-ray absorbing Co atom. The amplitude of the peak relates to the number of the ligands, and its position corresponds to the distance to the Co absorber. The distances that can be read directly from the FT plot are with $0.3-0.4 \AA$ shorter than the real distances [72,77]. The surrounding atom types, number, and distances can be determined by simulation of the recorded EXAFS oscillations (Table 1).

In solution, $\mathrm{Co}^{2+}$ binds to the oxygen atoms from the $\mathrm{OH}$ groups of the M2P ligand. Three possible structures for this coordination are shown in Fig. 3, b, c and d. The latter two have been observed in crystalline material [69]. In the FT of the Co/M2P precursor only one main peak is visible, which can be simulated with $\sim 6 \mathrm{Co}-\mathrm{O}$ distances of $2.1 \AA$, corresponding to octahedrally coordinated $\mathrm{Co}^{2+}$ ions [78]. This observation rules out the structure presented in Fig. 3c, where the Co ion is 5-coordinated.

Octahedral coordination is expected also for the Co ions, which are not bound to the ligand. To identify the presence of the bound M2P ligand, we should be able to resolve the Co-P distances predicted from the structures. Two Co-P distances at $3.3 \AA$ are expected for the structure in Fig. 3b and four such distances for the structure shown in Fig. 3d [69]. In the EXAFS simulation, $3.3 \AA$ Co-P vectors are indeed visible in the $\mathrm{Co} / \mathrm{M} 2 \mathrm{P}$ precursor with coordination number of around 2 (Table 1). The structure presented in Fig. 3d suggests also two Co-Co distances (per Co atom) of $3.7 \AA$, for which there is little support from the EXAFS simulations, but they cannot be excluded.

After illumination with visible light, the first Co-O peak shifts to shorter distances, in line with the increase in the Co oxidation state from +2 to +3 [78]. In the oxidized state, a second peak in the FT is clearly visible, which can be assigned to short Co-Co distances of about $2.8 \AA$ A. Such Co-Co distances are indicative of di- $\mu$-oxo bridged $\mathrm{Co}^{3+}$ ions [79-82]. The overall shape of the EXAFS spectrum shows similarity to the electrodeposited CoCat $[75-76,83]$. The peak at $5.2 \AA$ reduced distance corresponds to the doubled Co-Co distance $(2 \times 2.8 \AA=5.6 \AA)$ and exhibits a very high amplitude in the spectrum of crystalline layered $\mathrm{LiCoO}_{2}$ reference (Figure 2). This peak can be more easily resolved for the light-oxidized $\mathrm{Co} / \mathrm{M} 2 \mathrm{P}$ than for the CoCat, which indicates a higher degree of order than present in the electrodeposited Co oxide film. Otherwise the atomic structure of both compounds appears to be highly similar. 
The similarity of the spectrum of the Co/M2P nanoparticles obtained by light-oxidation of the $\mathrm{Co} / \mathrm{M} 2 \mathrm{P}$ precursor with the spectra of the $\mathrm{CoCat}$ and $\mathrm{LiCoO}_{2}$ (reference compound with layered structure) suggests that the nanoparticles contain, at the atomic level, Co-oxide fragments that consist of highly interconnected complete (closed) or incomplete (open) cubanes with $\mathrm{Co}$ and $\mathrm{O}$ atoms on the corners of the cubes [75]. The Co-P vector is still present in the nanoparticles obtained by light-oxidation of $\mathrm{Co} / \mathrm{M} 2 \mathrm{P}$ complexes, but the number of Co-P distances per Co atoms is decreased. This result points towards binding of the M2P ligand to only part of the Co atoms, presumably at the periphery of the complex.

While the cobalt $K$-edge XANES and EXAFS spectra reveal immediately the high similarity between the nanoparticle-catalyst and the electrodeposited CoCat with respect to its cobaltoxo structure, the identification of the binding mode of the M2P ligand is more difficult. The Co ligand environment was further studied with soft X-ray measurements at the cobalt $L$-edge and the oxygen $K$-edge, both being more informative with respect to metal ligands $[65,84-86]$.

\subsection{X-ray absorption spectroscopy at the cobalt L-edge}

In $L$-edge XAS, the relevant transitions involve core holes in the $2 s$ level ( $L_{1}$-edge) or $2 p$ levels ( $L_{2}$ - and $L_{3}$-edges) and final states in the $3 d$ level [87]. The positions of the peaks visible in the spectra shift to higher energies with increasing metal oxidation state [88-89] and the shape of the XAS spectra can be related to the electronic structure of the materials [8990].

Figure 4 shows the $L_{3^{-}}$and $L_{2}$-edges of the $\mathrm{Co} / \mathrm{M} 2 \mathrm{P}$ precursor as well as in the light-oxidized $\mathrm{Co} / \mathrm{M} 2 \mathrm{P}$, the spectral contribution of $\mathrm{Co}^{\mathrm{III}}$ ions to the oxidized sample of the $\mathrm{Co} / \mathrm{M} 2 \mathrm{P}$ catalyst, the spectrum of electrodeposited CoCat, and two reference compounds. When going from bottom ( $\mathrm{Co}^{\mathrm{II}}$ reference) to top ( $\mathrm{Co}^{\mathrm{III}}$ reference), the number of peaks decreases and the peak with highest intensity shifts to higher energies (dotted lines in Fig. 4). As the fluorescence yield is highest for the $L_{3}$-edge [91], we will focus our discussion at the part of the spectrum between $770 \mathrm{eV}$ and $785 \mathrm{eV}$.

The cobalt $L$-edge spectra confirm the results obtained at the cobalt $K$-edge, namely that the cobalt oxidation state in the $\mathrm{Co} / \mathrm{M} 2 \mathrm{P}$ precursor is +2 . We may suggest a high-spin electronic configuration because the spectrum of the precursor resembles the spectrum of a high-spin $\mathrm{Co}^{\mathrm{II}}$ reference (CoO in Fig. 4) [65,86-87] and also calculated spectra of high-spin $\mathrm{Co}^{\mathrm{II}}$ ions [90]. 
The interpretation of the spectrum from light-oxidized Co/M2P is less conclusive as for the $\mathrm{Co}^{\mathrm{II}}$ precursor. Upon light illumination, the Co oxidation state increases toward $\mathrm{Co}^{\mathrm{III}}$, but a $\mathrm{Co}^{\mathrm{II}}$ contribution is clearly visible for the colloidal Co/M2P. The cobalt $K$-edge position of a sample prepared by a similar protocol suggested a Co oxidation state of +3 , as discussed in section 3.1.1. (Fig. 1). The spectral contribution of the $\mathrm{Co}^{\mathrm{III}}$ ions in the $L$-edge spectrum can be revealed by subtracting the spectrum of the $\mathrm{Co} / \mathrm{M} 2 \mathrm{P}$ precursor from the spectrum of the light-oxidized Co/M2P (multiplied by a scaling factor, details given in the Supplementary Material). The result of this extraction is denoted as ' $\mathrm{Co}$ III/M2P' in Fig. 4. The thereby obtained spectrum of the $\mathrm{Co}^{\mathrm{III}}$ ions is similar to the spectrum of the electrodeposited CoCat, confirming the similarity between the Co/M2P nanoparticles and the electrodeposited CoCat. The ratio between the main peak and the low-energy and high-energy shoulders is different, possibly due to the present of the M2P ligand in the periphery of the Co oxide particles.

The $\mathrm{Co}^{\mathrm{II}}$ contribution in the spectrum of the light-oxidized $\mathrm{Co} / \mathrm{M} 2 \mathrm{P}$ material could relate the (largely unavoidable) handling of the material under ambient conditions during preparation of the sample for measurements at the $L$-edge; also X-ray photoreduction during data collection at room temperature might contribute [92]. The $K$-edge measurements most likely yield the correct oxidation state because the samples used for these measurements were preserved in liquid nitrogen immediately after preparation.

\subsection{X-ray absorption spectroscopy at the oxygen $K$-edge}

The features in the oxygen $K$-edge XANES arise from oxygen $2 p$ states that have contributions from partially occupied and unoccupied cobalt orbitals. Therefore oxygen $K$-edge XAS can probe directly the ligand-metal bond covalency [93]. The features in the preedge region ( $530 \mathrm{eV}$ and below) are assigned to transitions from the oxygen $1 \mathrm{~s}$ orbital to a hybridized state involving oxygen $2 p$ and predominantly cobalt $3 d$ states [84-85]. The main absorption edge and the region beyond it are attributed to transitions from the oxygen $1 s$ to hybridized orbitals of oxygen $2 p$ with cobalt $4 s$ and $4 p$ states $[66,85]$.

Detection of the oxygen $K$-edge spectra provides further insights into the role of the M2P ligands (Fig. 4). The oxygen XANES spectrum of the M2P ligand alone (without Co) is very similar to the spectrum of the $\mathrm{K}_{2} \mathrm{HPO}_{4}$ reference (Fig. 5). This can be predicted from the structure of the M2P ligand, which can be viewed as two phosphate groups bridged with a methylene residue $\left(-\mathrm{CH}_{2}-\right)$. Both in potassium phosphate and in the M2P ligand, oxygen has 
the same coordination environment. Binding of the Co to the M2P ligand in the precursor modifies only slightly the oxygen $K$-edge spectrum. This indicates that only a fraction of the oxygen atoms changes their coordination, likely by formation of $\mathrm{Co}-\mathrm{O}$ bonds, but without breakage of P-O bonds (see Fig. 2) [69].

Upon light oxidation, the Co/M2P spectrum changes significantly and becomes similar but not identical to the spectrum of the electrodeposited CoCat. The most dramatic change occurs in the pre-edge region, which is strongly influenced by the interaction between oxygen $2 p$ and metal $3 d$ orbitals [84-85]. The strong increase in the pre-edge suggests that major fractions of the oxygen atoms are coordinated to Co ions, such that Co-oxide fragments are formed in the light-oxidized $\mathrm{Co} / \mathrm{M} 2 \mathrm{P}$. The presence of two separate peaks visible in the pre-edge is attributed to the octahedral coordination of the cobalt ions. The octahedral crystal field of oxygen ions splits the energy level of the $3 d$-states of Co, into $e_{g}$ - and $t_{2 g}$-levels, with the $t_{2 g}-$ level being lower than the $\mathrm{e}_{\mathrm{g}}$-level [94]. Exchange interactions further split these states into spin-up $(\uparrow)$ and spin-down $(\downarrow)$ states. A more comprehensive understanding of the shape of the oxygen $K$-edge spectrum can be achieved by means of ab-initio DFT calculations [95-96], but this is beyond the scope of this article.

The oxygen $K$-edge spectrum of the light-oxidized Co/M2P is clearly different from the spectrum of the electrodeposited CoCat. We attribute the differences between the oxygen $K$-edge spectra of $\mathrm{Co} / \mathrm{M} 2 \mathrm{P}$ and CoCat to the presence of the M2P ligand in the former. Some of the oxygen atoms in the periphery of the complexes are bound only to phosphorus in form of oxo- or hydroxo groups, and as a result, the main edge shifts toward lower energies, as in the pure M2P ligand.

\section{Discussion}

The goal of this study was to gain insight into the atomic structure of water-oxidizing cobalt oxide nanoparticles which have been shown previously to be limited in size to $10-60 \mathrm{~nm}$ radius by employment of a M2P ligand [46]. We performed XAS measurements at the cobalt and oxygen absorption edges. The XAS measurements of the cobalt $K$-edge reveal a cobaltoxide core structure similar to that of the electrodeposited CoCat films [75-76,83]. In both catalysts, octahedrally coordinated $\mathrm{Co}^{\mathrm{III}}$ ions likely form fragments of a layered cobalt oxide characterized by extensive di- $\mu$-oxo bridging (edge-sharing of $\mathrm{CoO}_{6}$ octahedra); the presence of $\mathrm{Co}_{4}\left(\mu-\mathrm{O}_{4}\right)$ cubanes cannot be excluded. The size or intrinsic order of the oxide fragments 
appears to be higher in the nanoparticles than in the electrodeposited CoCat film. However, this is not indicative of a principal structural difference as also for electro-deposited CoCat films the cluster size has been found to vary, depending on the anions used during the electrodeposition procedure [97].

The XAS experiments with hard X-rays at the cobalt $K$-edge alone provide only insufficient information about the binding of the M2P ligand, as the EXAFS peaks related to backscattering of the photoelectron by phosphorous are close to the noise level. The XAS experiments with soft $\mathrm{X}$-rays at the cobalt $L$-edge and oxygen $K$-edge support a specific mode of binding of the M2P ligand to the catalytically active Co-oxide core.

The XAS data, especially the oxygen $K$-edge spectra, suggest that the M2P ligand is coordinated to Co ions also in nanoparticles obtained by light-oxidation of the Co/M2P complex. (We cannot exclude definitively that the M2P ligand does not bind to the cobalt oxide core at all but forms a separate phase; however, we consider this option to be clearly less likely.) Formation of much larger particles (agglomerates) of Co oxide of micrometer size upon light illumination is observed when the M2P ligand is not present in the solution [46]. This observation in conjunction with the herein reported XAS results suggesting that M2P ligands bind preferentially at the edges (periphery) of the Co oxides nanoparticles preventing formation of large agglomerates.

Figure 6 shows an illustration of a possible building block of the colloidal nanoparticles. The shown model satisfies the constraints for Co-O, Co-Co and Co-P vectors given by EXAFS simulations (Table 1). Note that the representation of the atomic structure in Fig. 6 is highly idealized. The real particles exhibit a size of 10-60 nm, as found by light-scattering experiments [46]. Thus, it clearly exceeds the size of the planar structure shown in Fig. 6. The particles size of 10-60 nm may be explainable by formation of stacks of cobalt-oxide layer fragments which are similar to the one shown in Fig. 6.

The herein identified Co-oxo core structure of the $\mathrm{Co} / \mathrm{M} 2 \mathrm{P}$ nanoparticles and of the electrodeposited CoCat exhibit structural motifs also found in the Mn-Ca core of the oxygenevolving complex (OEC) of the biological catalysts in oxygenic photosynthesis (with Co instead of Mn). The electrodeposited CoCat, however, is an extended solid-state material. It is not well suited for employment in synthetic systems that mimic photosynthetic water oxidation by attachment of a photosensitizer to the catalyst. In the biological system (PSII), the photosensitizers are chlorophyll molecules, linked by the protein matrix of PSII to the $\mathrm{Mn}_{4} \mathrm{O}_{5} \mathrm{Ca}$ core of the OEC [9,11-13]. 
To mimic the biological process closely, the photosensitizer molecule (in this case $\left[\mathrm{Ru}(\mathrm{bpy})_{3}\right]^{2+}$ ) needs to be bound covalently to the Co-oxide catalysts employing a molecular linker. In future systems, a modified M2P ligand can serve as an anchor point for the molecular linker. For such biomimetic system the small particle size of the Co/M2P core is of high importance for more efficient coupling between the photosensitizer and the nanoparticle, as it will allow binding of more electron acceptors per Co atom. Furthermore, it was suggested that smaller cluster sizes are beneficial for high water-oxidation activity [97].

\section{Conclusions}

The Co/M2P catalytic system studied here is an important step toward development of an artificial catalyst, which mimics the water oxidation function of Photosystem II in green plants and cyanobacteria. By employing X-ray absorption spectroscopy at multiple absorption edges we showed that the catalytically active part of the $\mathrm{Co} / \mathrm{M} 2 \mathrm{P}$ complex is $\mathrm{Co}^{\mathrm{III}}$ oxide with a structure similar to the structure reported previously for the electrochemically deposited CoCat [75-76]. The M2P molecules bind as ligands at the periphery of the oxide particles, preventing in this way their agglomeration upon light oxidation. After appropriate chemical modification these M2P ligands can be used to connect directly the photosensitizer to the catalytically active particles thus building a system for direct utilization of the solar energy. Despite the long way to go to its practical application, the approach described in this article could pave the road for development of a colloidal catalytic system for light-driven water oxidation.

\section{Acknowledgements}

We thank F. Schäfers and M. Mertin (beamline KMC-1, BESSY, Berlin) as well as R.

Könnecke, K. Hodeck and E. F. Aziz (beamline U41PGM, BESSY, Berlin) for excellent technical support and H. Dau (FU Berlin) for valuable discussions. We gratefully acknowledge support by the Berlin Cluster of Excellence on Unifying Concepts in Catalysis (UniCat), the European Union ( $7^{\text {th }}$ Framework Program, SOLAR-H2 consortium, grant 212508), the German 'Bundesministerium für Bildung und Forschung' (BMBF, $H_{2}$ Design cell consortium, grant 03SF0355D), the Swedish Energy Agency, Knut and Alice Wallenberg Foundation, and a Marie Curie International Incoming Fellowship within the 7th European Community Framework Programme, contract no 236511 FP7-PEOPLE-IIF-2008 (for DS). 


\section{Footnotes}

${ }^{1} \mathrm{H}_{4} \mathrm{M} 2 \mathrm{P}$ is the fully protonated methylenediphosphonic acid $\left(\mathrm{H}_{2} \mathrm{O}_{3} \mathrm{PCH}_{2} \mathrm{PO}_{3} \mathrm{H}_{2}\right)$. At pH 7 the $\mathrm{HM} 2 \mathrm{P}^{3-}$ and $\mathrm{H}_{2} \mathrm{M} 2 \mathrm{P}^{2-}$ forms dominate, for brevity $\mathrm{M} 2 \mathrm{P}$ will be used to indicate all protonation states.

\section{References}

[1] Mann ME, Bradley RS, Hughes MK. Global-scale temperature patterns and climate forcing over the past six centuries. Nature 1998;392:779-87.

[2] Mann ME, Bradley RS, Hughes MK, Jones PD. Global temperature patterns. Science 1998;280:2029-30.

[3] Solomon S, Qin D, Manning M, Chen Z, Marquis M, Averyt KB, et al. Climate Change 2007: The Physical Science Basis - Contribution of Working Group I to the Fourth Assessment Report of the Intergovernmental Panel on Climate Change Cambridge University Press; 2007.

[4] Lewis NS, Nocera DG. Powering the planet: chemical challenges in solar energy utilization. Proc Natl Acad Sci USA 2006;103:15729-35.

[5] Dau H, Limberg C, Reier T, Risch M, Roggan S, Strasser P. The mechanism of water oxidation: from electrolysis via homogeneous to biological catalysis. ChemCatChem 2010;2:724-61.

[6] Ort D, Yocum CF. Oxygenic photosynthesis: The light reactions, vol 10. Edited by Govindjee. Dordrecht: Kluwer Academic Publ.; 1996.

[7] Blankenship RE. Molecular mechanisms of photosynthesis. Oxford, England: Blackwell Science; 2002.

[8] Barber J. Photosystem II: a multisubunit membrane protein that oxidises water. Curr Opin Struct Biol 2002;12:523-30.

[9] Penner-Hahn JE. Structural characterization of the Mn site in the photosynthetic oxygenevolving complex. In: Hill HAO, Sadler PJ, Thomson AJ, editors. Metal Sites in Proteins and Models: Redox Centres, Berlin / Heidelberg, Germany: Springer; 1999, p. 1-36.

[10] McEvoy JP, Brudvig GW. Water-splitting chemistry of photosystem II. Chem Rev 2006;106:4455-83.

[11] Dau H, Haumann M. The manganese complex of photosystem II in its reaction cyclebasic framework and possible realization at the atomic level. Coord Chem Rev 2008;252:273-95.

[12] Dau H, Zaharieva I. Principles, efficiency, and blueprint character of solar-energy conversion in photosynthetic water oxidation. Acc Chem Res 2009;42:1861-70.

[13] Umena Y, Kawakami K, Shen J-R, Kamiya N. Crystal structure of oxygen-evolving photosystem II at a resolution of $1.9 \AA$. Nature 2011;473:55-60.

[14] Grundmeier A, Dau H. Structural models of the manganese complex of photosystem II and mechanistic implications. Biochim Biophys Acta 2012;1817:88-105.

[15] Shafirovich VY, Khannanov NK, Shilov AE. Inorganic models of photosystem II of plant photosynthesis. Catalytic and photocatalytic oxidation of water with participation of manganese compounds. J Inorg Biochem 1981;15:113-29.

[16] Limburg J, Vrettos JS, Liable-Sands LM, Rheingold AL, Crabtree RH, Brudvig GW. A functional model for $\mathrm{O}-\mathrm{O}$ bond formation by the $\mathrm{O}_{2}$-evolving complex in photosystem II. Science 1999;283:1524-7. 
[17] Yagi M, Narita K. Catalytic $\mathrm{O}_{2}$ Evolution from Water Induced by Adsorption of $\left[\left(\mathrm{OH}_{2}\right) \text { (Terpy) } \mathrm{Mn}(-\mathrm{O})_{2} \mathrm{Mn}(\mathrm{Terpy})\left(\mathrm{OH}_{2}\right)\right]^{3+}$ Complex onto Clay Compounds. J Am Chem Soc 2004;126:8084-5.

[18] Magnuson A, Liebisch P, Hogblom J, Anderlund MF, Lomoth R, Meyer-Klaucke W, et al. Bridging-type changes facilitate successive oxidation steps at about $1 \mathrm{~V}$ in two binuclear manganese complexes - Implications for photosynthetic water-oxidation. $\mathbf{J}$ Inorg Biochem 2006;100:1234-43.

[19] Chen H, Tagore R, Olack G, Vrettos JS, Weng TC, Penner-Hahn J, et al. Speciation of the catalytic oxygen evolution system: $\left[\mathrm{Mn}^{\mathrm{III} / \mathrm{IV} 2}(\mathrm{mu}-\mathrm{O})_{2}(\text { terpy })_{2}\left(\mathrm{H}_{2} \mathrm{O}\right)_{2}\right]\left(\mathrm{NO}_{3}\right)_{3}+$ $\mathrm{HSO}_{5}$. Inorg Chem 2007;46:34-43.

[20] El-Deab MS, Awad MI, Mohammad AM, Ohsaka T. Enhanced water electrolysis: Electrocatalytic generation of oxygen gas at manganese oxide nanorods modified electrodes. Electrochem Commun 2007;9:2082-7.

[21] Kurz P, Berggren G, Anderlund MF, Styring S. Oxygen evolving reactions catalysed by synthetic manganese complexes: A systematic screening. Dalton Trans 2007;38:425861.

[22] Beckmann K, Uchtenhagen H, Berggren G, Anderlund MF, Thapper A, Messinger J, et al. Formation of stoichiometrically (18)O-labelled oxygen from the oxidation of (18)O-enriched water mediated by a dinuclear manganese complex - a mass spectrometry and EPR study. Energy Environ Sci 2008;1:668-76.

[23] Herrero C, Lassalle-Kaiser B, Leibl W, Rutherford AW, Aukauloo A. Artificial systems related to light driven electron transfer processes in PSII. Coord Chem Rev 2008;252:456-68.

[24] Berggren G, Thapper A, Huang P, Kurz P, Eriksson L, Styring S, et al. Two tetranuclear Mn-complexes as biomimetic models of the oxygen evolving complex in photosystem II. A synthesis, characterisation and reactivity study. Dalton Trans 2009;45:10044 54.

[25] Brimblecombe R, Koo A, Dismukes GC, Swiegers GF, Spiccia L. Solar driven water oxidation by a bioinspired manganese molecular catalyst. J Am Chem Soc 2010;132:2892-4.

[26] Jiao F, Frei H. Nanostructured manganese oxide clusters supported on mesoporous silica as efficient oxygen-evolving catalysts. Chem Commun 2010;46:2920-2.

[27] Gorlin Y, Jaramillo TF. A bifunctional nonprecious metal catalyst for oxygen reduction and water oxidation. J Am Chem Soc 2010;132:13612-4.

[28] Najafpour Mohammad M, Ehrenberg T, Wiechen M, Kurz P. Calcium manganese(III) oxides $\left(\mathrm{CaMn}_{2} \mathrm{O}_{4} \cdot x \mathrm{H}_{2} \mathrm{O}\right)$ as biomimetic oxygen-evolving catalysts. Angew Chem Int Ed 2010;49:2233-7.

[29] Hocking RK, Brimblecombe R, Chang L-Y, Singh A, Cheah MH, Glover C, et al. Wateroxidation catalysis by manganese in a geochemical-like cycle. Nat Chem 2011;3:4616.

[30] Kanady JS, Tsui EY, Day MW, Agapie T. A Synthetic model of the $\mathrm{Mn}_{3} \mathrm{Ca}$ subsite of the oxygen-evolving complex in photosystem II. Science 2011;333:733-6.

[31] El Ghachtouli S, Lassalle-Kaiser B, Dorlet P, Guillot R, Anxolabehere-Mallart E, Costentin C, et al. Implications of remote water molecules on the electron transfer coupled processes at a nonporphyrinic Mn(III)-hydroxido complex. Energy Environ Sci 2011;4:2041-4.

[32] Wiechen M, Berends H-M, Kurz P. Water oxidation catalysed by manganese compounds: from complexes to 'biomimetic rocks'. Dalton Trans 2012.

[33] Harriman A, Pickering IJ, Thomas JM, Christensen PA. Metal-oxides as heterogeneous catalysts for oxygen evolution under photochemical conditions. J Chem Soc-Farad T 1 1988;84:2795-806. 
[34] Lachaud F, Quaranta A, Pellegrin Y, Dorlet P, Charlot MF, Un S, et al. A biomimetic model of the electron transfer between P680 and the TyrZ-His190 pair of PSII. Angew Chem Int Ed Engl 2005;44:1536-40.

[35] Sala X, Romero I, Rodriguez M, Escriche L, Llobet A. Molecular catalysts that oxidize water to dioxygen. Angew Chem Int Ed 2009;48:2842-52.

[36] Duan L, Xu Y, Zhang P, Wang M, Sun L. Visible light-driven water oxidation by a mononuclear ruthenium catalyst in homogeneous system. Inorg Chem 2010;49:20915.

[37] Blakemore JD, Schley ND, Balcells D, Hull JF, Olack GW, Incarvito CD, et al. Halfsandwich iridium complexes for homogeneous water-oxidation catalysis. J Am Chem Soc 2010;132:16017-29.

[38] Roeser S, Farràs P, Bozoglian F, Martínez-Belmonte M, Benet-Buchholz J, Llobet A. Chemical, electrochemical, and photochemical catalytic oxidation of water to dioxygen with mononuclear ruthenium complexes. ChemSusChem 2011;4:197-207.

[39] Herrero C, Quaranta A, Leibl W, Rutherford AW, Aukauloo A. Artificial photosynthetic systems. Using light and water to provide electrons and protons for the synthesis of a fuel. Energy Environ Sci 2011;4:2353-65.

[40] Singh RN, Mishra D, Anindita, Sinha ASK, Singh A. Novel electrocatalysts for generating oxygen from alkaline water electrolysis. Electrochem Commun 2007;9:1369-73.

[41] Kanan MW, Nocera DG. In situ formation of an oxygen-evolving catalyst in neutral water containing phosphate and $\mathrm{Co}^{2+}$. Science 2008;321:1072-5.

[42] Jiao F, Frei H. Nanostructured cobalt oxide clusters in mesoporous silica as efficient oxygen-evolving catalysts. Angew Chem Int Ed 2009;48:1841-4.

[43] Yin Q, Tan JM, Besson C, Geletii YV, Musaev DG, Kuznetsov AE, et al. A fast soluble carbon-free molecular water oxidation catalyst based on abundant metals. Science 2010:342-5.

[44] Wee T-L, Sherman BD, Gust D, Moore AL, Moore TA, Liu Y, et al. Photochemical synthesis of a water oxidation catalyst based on cobalt nanostructures. J Am Chem Soc 2011;133:16742-5.

[45] Yeo BS, Bell AT. Enhanced activity of gold-supported cobalt oxide for the electrochemical evolution of oxygen. J Am Chem Soc 2011;133:5587-93.

[46] Shevchenko D, Anderlund MF, Thapper A, Styring S. Photochemical water oxidation with visible light using a cobalt containing catalyst. Energy Environ Sci 2011;4:12847.

[47] Surendranath Y, Dinca M, Nocera DG. Electrolyte-dependent electrosynthesis and activity of cobalt-based water oxidation catalysts. J Am Chem Soc 2009;131:2615-20.

[48] Shafirovich VJ, Khannanov NK, Strelets VV. Photosensitized water oxidation by visiblelight with the participation of transition-metal complexes. Dokl Akad Nauk SSSR 1980;250:1197-200.

[49] Shafirovich VY, Khannanov NK, Strelets VV. Chemical and light-induced catalytic water oxidation. New J Chem 1980;4:81-4.

[50] Elizarova GL, Matvienko LG, Lozhkina NV, Parmon VN, Zamaraev KI. Homogeneous catalysts for dioxygen evolution from water - water oxidation by trisbipyridylruthenium(III) in the presence of cobalt, iron and copper-complexes. React Kinet Catal Lett 1981;16:191-4.

[51] Gerasimov OV, Elizarova GL, Parmon VN. Photosensitized water oxidation to dioxygen in artificial biomimetic systems - achievements and prospects. J Photochem Photobiol B 1992;13:335-8.

[52] Elizarova GL, Zhidomirov GM, Parmon VN. Hydroxides of transition metals as artificial catalysts for oxidation of water to dioxygen. Catal Today 2000;58:71-88. 
[53] Jiao F, Frei H. Nanostructured cobalt and manganese oxide clusters as efficient water oxidation catalysts. Energy Environ Sci 2010;3:1018-27.

[54] Zhong DK, Sun JW, Inumaru H, Gamelin DR. Solar water oxidation by composite catalyst $/ \alpha-\mathrm{Fe}_{2} \mathrm{O}_{3}$ photoanodes. J Am Chem Soc 2009;131:6086-7.

[55] Zhong DK, Gamelin DR. Photoelectrochemical water oxidation by cobalt catalyst ("Co-Pi") $/ \alpha-\mathrm{Fe}_{2} \mathrm{O}_{3}$ composite photoanodes: Oxygen evolution and resolution of a kinetic bottleneck. J Am Chem Soc 2010;132:4202-7.

[56] Zhong DK, Cornuz M, Sivula K, Graetzel M, Gamelin DR. Photo-assisted electrodeposition of cobalt-phosphate (Co-Pi) catalyst on hematite photoanodes for solar water oxidation. Energy Environ Sci 2011;4:1759-64.

[57] Barroso M, Cowan AJ, Pendlebury SR, Grätzel M, Klug DR, Durrant JR. The role of cobalt phosphate in enhancing the photocatalytic activity of $\alpha-\mathrm{Fe}_{2} \mathrm{O}_{3}$ toward water oxidation. J Am Chem Soc 2011;133:14868-71.

[58] McDonald KJ, Choi KS. Photodeposition of Co-based oxygen evolution catalysts on $\alpha-$ $\mathrm{Fe}_{2} \mathrm{O}_{3}$ photoanodes. Chem Mater 2011;23:1686-93.

[59] Steinmiller EMP, Choi KS. Photochemical deposition of cobalt-based oxygen evolving catalyst on a semiconductor photoanode for solar oxygen production. Proc Natl Acad Sci USA 2009;106:20633-6.

[60] Seabold JA, Choi KS. Effect of a cobalt-based oxygen evolution catalyst on the stability and the selectivity of photo-oxidation reactions of a $\mathrm{WO}_{3}$ photoanode. Chem Mater 2011;23:1105-12.

[61] Zhong DK, Choi S, Gamelin DR. Near-complete suppression of surface recombination in solar photoelectrolysis by "Co-Pi" catalyst-modified W:BiVO 4 . J Am Chem Soc 2011;133:18370-7.

[62] Reece SY, Hamel JA, Sung K, Jarvi TD, Esswein AJ, Pijpers JJH, et al. Wireless solar water splitting using silicon-based semiconductors and earth-abundant catalysts. Science 2011;334:645-8

[63] Pijpers JJH, Winkler MT, Surendranath Y, Buonassisi T, Nocera DG. Light-induced water oxidation at silicon electrodes functionalized with a cobalt oxygen-evolving catalyst. Proc Natl Acad Sci USA 2011;108:10056-61.

[64] Young ER, Costi R, Paydavosi S, Nocera DG, Bulovic V. Photo-assisted water oxidation with cobalt-based catalyst formed from thin-film cobalt metal on silicon photoanodes. Energy Environ Sci 2011;4:2058-61.

[65] de Groot FMF, Abbate M, van Elp J, Sawatzky GA, Ma GA, Chen CT, et al. Oxygen 1s and cobalt 2p X-ray absorption of cobalt oxides. J Phys: Condens Matter 1993;5:2277.

[66] Yoon W-S, Kim K-B, Kim M-G, Lee M-K, Shin H-J, Lee J-M, et al. Oxygen contribution on Li-Ion intercalation-deintercalation in $\mathrm{LiCoO}_{2}$ investigated by $\mathrm{O} \mathrm{K}$ edge and Co L-edge X-ray absorption spectroscopy. J Phys Chem B 2002;106:252632 .

[67] Mohamady S, Jakeman DL. An improved method for the synthesis of nucleoside triphosphate analogues. J Org Chem 2005;70:10588-91.

[68] Aziz EF, Ottosson N, Bonhommeau S, Bergmann N, Eberhardt W, Chergui M. Probing the electronic structure of the hemoglobin active center in physiological solutions. Phys Rev Lett 2009;102:068103.

[69] Distler A, L. Lohse D, C. Sevov S. Chains, planes, and tunnels of metal diphosphonates: synthesis, structure, and characterization of $\mathrm{Na}_{3} \mathrm{Co}\left(\mathrm{O}_{3} \mathrm{PCH}_{2} \mathrm{PO}_{3}\right)(\mathrm{OH})$, $\mathrm{Na}_{3} \mathrm{Mg}\left(\mathrm{O}_{3} \mathrm{PCH}_{2} \mathrm{PO}_{3}\right) \mathrm{F} \cdot \mathrm{H}_{2} \mathrm{O}, \mathrm{Na}_{2} \mathrm{Co}\left(\mathrm{O}_{3} \mathrm{PCH}_{2} \mathrm{PO}_{3}\right) \cdot \mathrm{H}_{2} \mathrm{O}, \mathrm{NaCo}_{2}\left(\mathrm{O}_{3} \mathrm{PCH}_{2} \mathrm{CH}_{2} \mathrm{CH}_{2} \mathrm{PO}_{3}\right)$ $(\mathrm{OH})$, and $\mathrm{Co}_{2}\left(\mathrm{O}_{3} \mathrm{PCH}_{2} \mathrm{PO}_{3}\right)\left(\mathrm{H}_{2} \mathrm{O}\right)$. J Chem Soc Dalton 1999:1805-12.

[70] Dau H, Liebisch P, Haumann M. X-ray absorption spectroscopy to analyze nuclear geometry and electronic structure of biological metal centers - potential and questions 
examined with special focus on the tetra-nuclear manganese complex of oxygenic photosynthesis. Anal Bioanal Chem 2003;376:562-83.

[71] Yamamoto T. Assignment of pre-edge peaks in K-edge X-ray absorption spectra of $3 \mathrm{~d}$ transition metal compounds: electric dipole or quadrupole? X-Ray Spectrom 2008;37:572-84.

[72] Teo B. EXAFS: Basic principles and data analysis. Berlin, Germany: Springer Verlag; 1986.

[73] Kau LS, Spira-Solomon DJ, Penner-Hahn JE, Hodgson KO, Solomon EI. X-ray absorption edge determination of the oxidation state and coordination number of copper. Application to the type 3 site in Rhus vernicifera laccase and its reaction with oxygen. J Am Chem Soc 1987;109:6433-42.

[74] Natoli CR. Near edge structure III, vol 2: Springer; 1984.

[75] Risch M, Khare V, Zaharieva I, Gerencser L, Chernev P, Dau H. Cobalt-oxo core of a water-oxidizing catalyst film. J Am Chem Soc 2009;131:6936-7.

[76] Kanan MW, Yano J, Surendranath Y, Dinca M, Yachandra VK, Nocera DG. Structure and valency of a cobalt-phosphate water oxidation catalyst determined by in situ X-ray spectroscopy. J Am Chem Soc 2010;132:13692-701.

[77] Penner-Hahn JE. X-ray absorption spectroscopy in coordination chemistry. Coord Chem Rev 1999;190-192:1101-23.

[78] Wood RM, Palenik GJ. Bond valence sums in coordination chemistry: A simple method for calculating the oxidation state of cobalt in complexes containing only $\mathrm{Co}-\mathrm{O}$ bonds. Inorg Chem 1998;37:4149-51.

[79] Masset AC, Michel C, Maignan A, Hervieu M, Toulemonde O, Studer F, et al. Misfitlayered cobaltite with an anisotropic giant magnetoresistance: $\mathrm{Ca}_{3} \mathrm{Co}_{4} \mathrm{O}_{9}$. Phys Rev B 2000;62:166.

[80] Ama T, Rashid MM, Yonemura T, Kawaguchi H, Yasui T. Cobalt(III) complexes containing incomplete $\mathrm{Co}_{3} \mathrm{O}_{4}$ or complete $\mathrm{Co}_{4} \mathrm{O}_{4}$ cubane core. Coord Chem Rev 2000;198:101-16.

[81] Ama T, Yonemura T, Morita S, Yamaguchi M. Pentaaquatri- $\mu_{3}$-hydroxidotris(iminodiacetato)- $\mu_{3}$-oxido-tetrahedro-calcium(II)tricobalt(III) 2.54-hydrate. Acta Cryst E 2010;66:M483-U1364.

[82] Hertz JT, Huang Q, McQueen T, Klimczuk T, Bos JWG, Viciu L, et al. Magnetism and structure of $\mathrm{Li}_{x} \mathrm{CoO}_{2}$ and comparison to $\mathrm{Na}_{\mathrm{x}} \mathrm{CoO}_{2}$. Phys Rev B 2008;77:075119.

[83] Risch M, Ringleb F, Khare V, Chernev P, Zaharieva I, Dau H. Characterisation of a water-oxidizing Co-film by XAFS. J Physics: Conf Series 2009;190:012167.

[84] Grunes LA, Leapman RD, Wilker CN, Hoffmann R, Kunz AB. Oxygen-K near-edge fine-structure - An electron-energy-loss investigation with comparisons to new theory for selected 3d transition-metal oxides. Phys Rev B 1982;25:7157-73.

[85] de Groot FMF, Grioni M, Fuggle JC, Ghijsen J, Sawatzky GA, Petersen H. Oxygen 1s xray-absorption edges of transition-metal oxides. Phys Rev B 1989;40:5715.

[86] Morales F, de Groot FMF, Glatzel P, Kleimenov E, Bluhm H, Hävecker M, et al. In situ $\mathrm{X}$-ray absorption of $\mathrm{Co} / \mathrm{Mn} / \mathrm{TiO}_{2}$ catalysts for Fischer-Tropsch synthesis. J Phys Chem B 2004;108:16201-7.

[87] de Groot F, Kotani A. Core Level Spectroscopy of Solids, vol 6: CRC; 2008.

[88] Cressey G, Henderson CMB, Vanderlaan G. Use of L-edge X-ray-absorption spectroscopy to characterize multiple valence states of $3 \mathrm{~d}$ transition-metals - a new probe for mineralogical and geochemical research. Phys Chem Miner 1993;20:111-9.

[89] Grush MM, Chen J, Stemmler TL, George SJ, Ralston CY, Stibrany RT, et al. Manganese L-edge X-ray absorption spectroscopy of manganese catalase from Lactobacillus plantarum and mixed valence manganese complexes. J Am Chem Soc 1996;118:65-9. 
[90] de Groot FMF, Fuggle JC, Thole BT, Sawatzky GA. 2p X-ray absorption of 3d transition-metal compounds - an atomic multiplet description including the crystalfield. Phys Rev B 1990;42:5459-68.

[91] Krause MO. Atomic radiative and radiationless yields for K-shells and L-shells. J Phys Chem Ref Data 1979;8:307-27.

[92] Grabolle M, Haumann M, Müller C, Liebisch P, Dau H. Rapid loss of structural motifs in the manganese complex of oxygenic photosynthesis by X-ray irradiation at 10-300 K. J Biol Chem 2006;281:4580-8.

[93] Solomon EI, Hedman B, Hodgson KO, Dey A, Szilagyi RK. Ligand K-edge X-ray absorption spectroscopy: covalency of ligand-metal bonds. Coord Chem Rev 2005;249:97-129.

[94] Winter MJ. d-Block Chemistry: Oxford University Press; 1994.

[95] Czyżyk MT, Potze R, Sawatzky GA. Band-theory description of high-energy spectroscopy and the electronic structure of $\mathrm{LiCoO}_{2}$. Phys Rev B 1992;46:3729.

[96] Juhin A, de Groot F, Vanko G, Calandra M, Brouder C. Angular dependence of core hole screening in $\mathrm{LiCoO}_{2}$ : A DFT+U calculation of the oxygen and cobalt $\mathrm{K}$-edge X-ray absorption spectra. Phys Rev B 2010;81.

[97] Risch M, Klingan K, Ringleb F, Chernev P, Zaharieva I, Fischer A, et al. Water oxidation by electro-deposited cobalt oxides - Role of anions and redox-inert cations for structure and function of the amorphous catalyst. ChemSusChem 2011:, in print.

[98] Risch M, Klingan K, Heidkamp J, Ehrenberg D, Chernev P, Zaharieva I, et al. Nickeloxido structure of a water-oxidizing catalyst film. Chem Commun 2011;47:11912-4.

[99] Haromy TP, Knight WB, Dunaway-Mariano D, Sundaralingam M. Crystal structure and molecular conformation of $\mathrm{P}^{1}, \mathrm{P}^{2}$-bidentate tetraammine(methylenediphosphato) cobalt(III) hydrochloride (CoPCP): $\mathrm{CoH}_{2} \mathrm{P}_{2} \mathrm{O}_{6} \mathrm{CH}_{2}\left(\mathrm{NH}_{3}\right)^{4+}$. $\mathrm{Cl}^{-}$. Inorg Chem 1984;23:2412-5. 
Figures

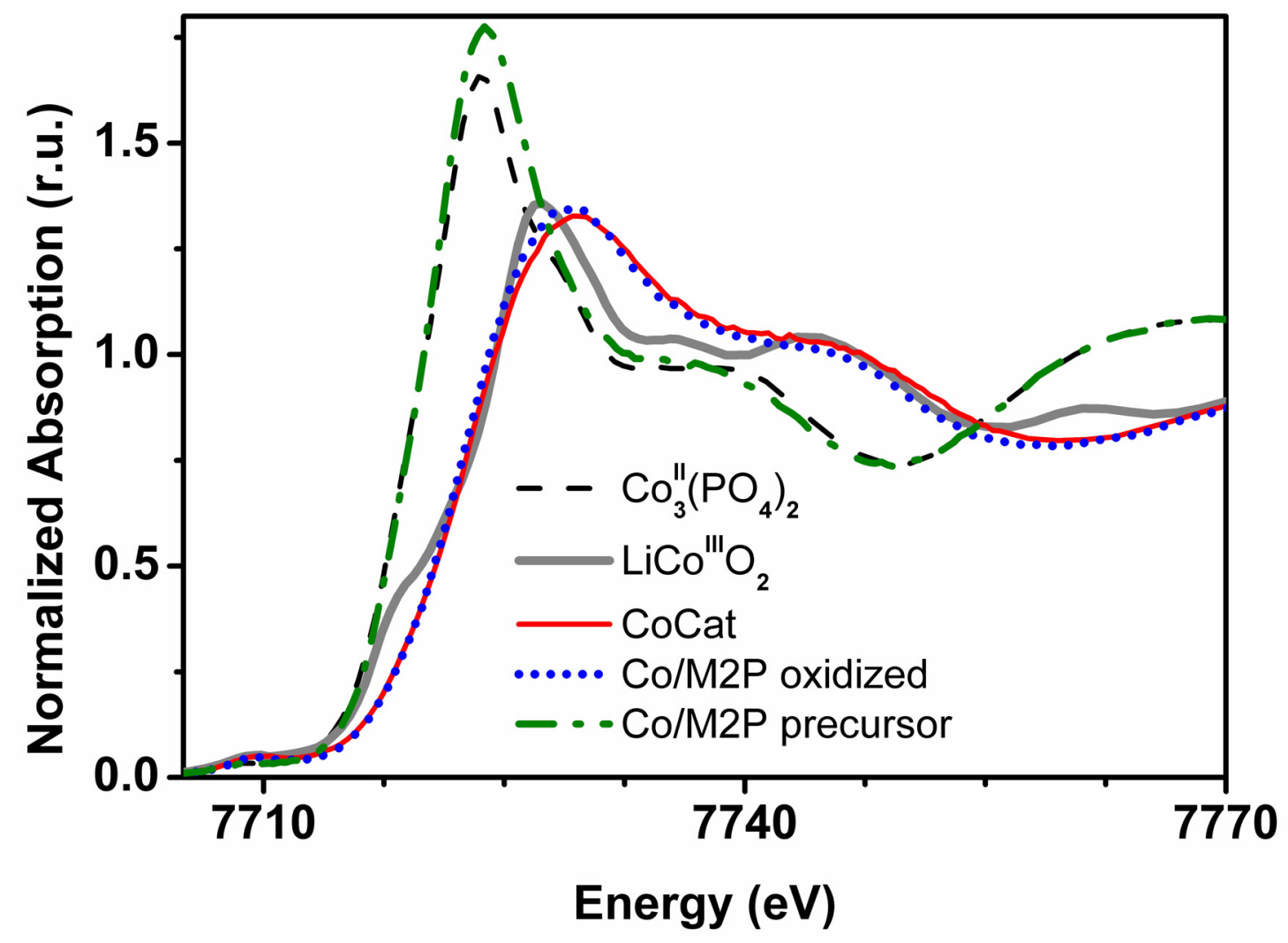

Figure 1. XANES spectra measured at the cobalt $K$-edge. The spectra of Co/M2P in the precursor complex and upon light oxidation are compared to the spectra of the electrodeposited CoCat and two reference compounds, $\mathrm{Co}_{3}{ }_{3}\left(\mathrm{PO}_{4}\right)_{2}$ and $\mathrm{LiCo}^{\mathrm{III}} \mathrm{O}_{2}$. The position of the edge rise is indicative for the mean oxidation state of the Co ions. 


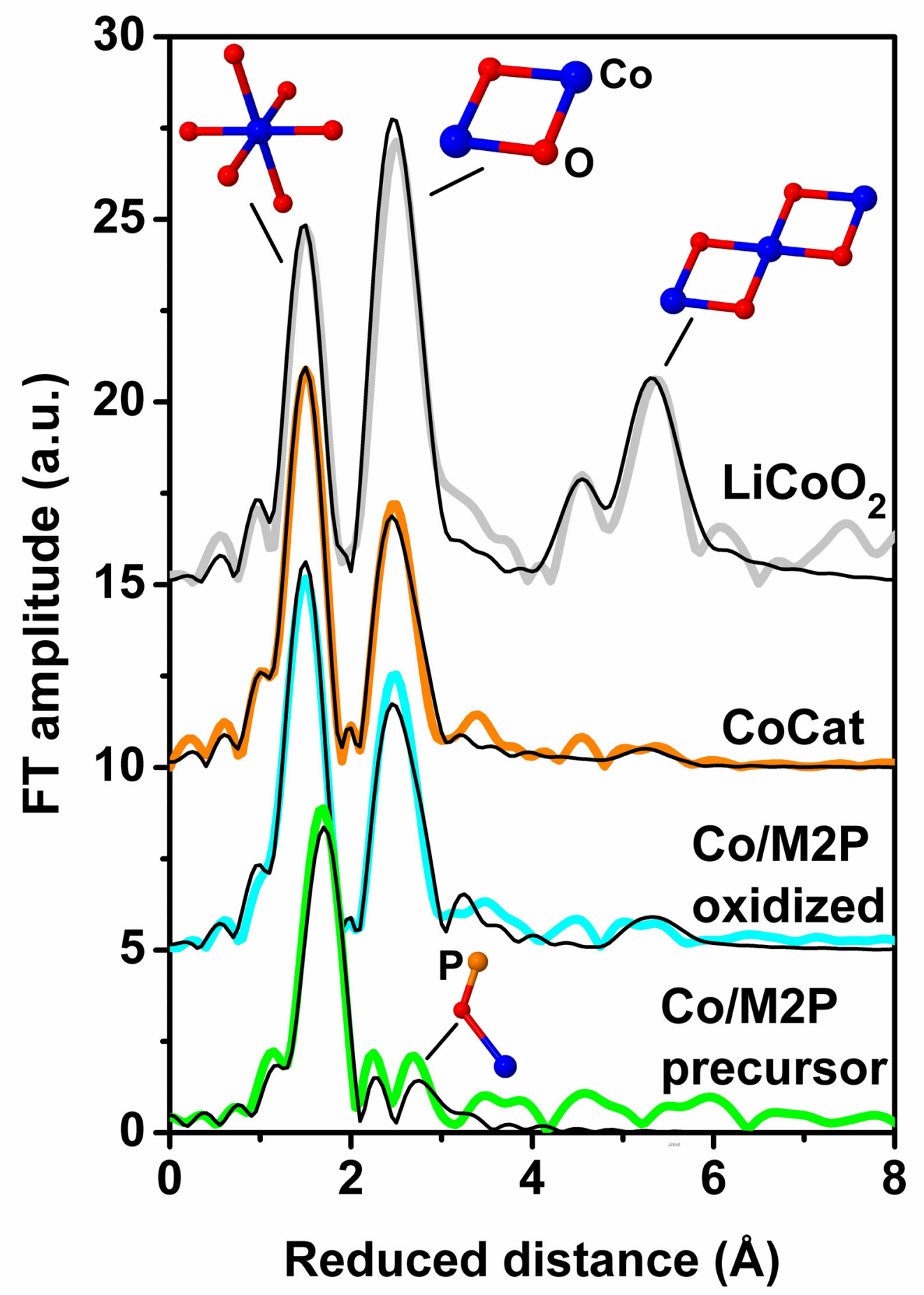

Figure 2. Fourier transformed EXAFS spectra measured at the cobalt $K$-edge (from top to bottom: $\mathrm{LiCoO}_{2}$, CoCat, light oxidized $\mathrm{Co} / \mathrm{M} 2 \mathrm{P}, \mathrm{Co} / \mathrm{M} 2 \mathrm{P}$ precursor). Simulations are shown as thin black lines (see Table 1 for the simulation parameters; the simulation parameters for the $\mathrm{LiCoO}_{2}$ are given in the Supplementary Material). The structural motifs corresponding to main peaks in the Fourier transformed EXAFS spectra are also shown. 
<smiles>O=P(O)(O)CP(=O)(O)O</smiles><smiles>O=P1(O)OC23OP(=O)(O2)OP(=O)(O3)O1</smiles>
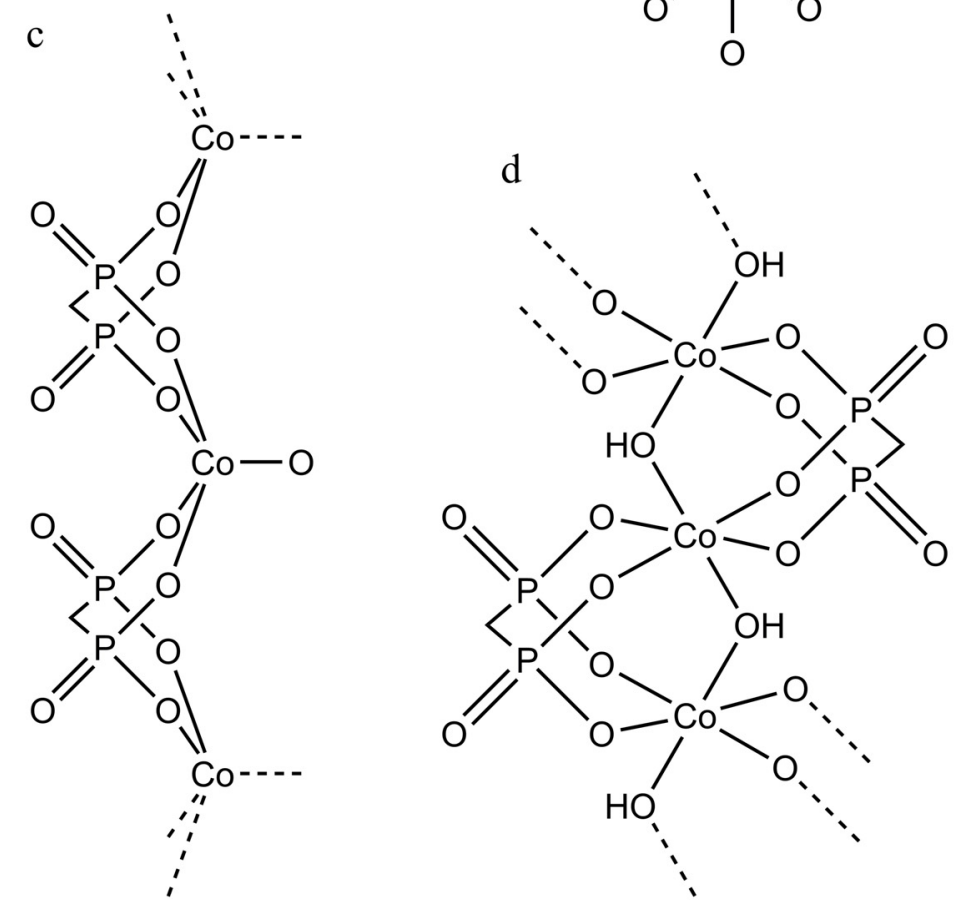

Figure 3. Co-M2P binding motifs. (a) $\mathrm{H}_{4} \mathrm{M} 2 \mathrm{P}$, (b) possible Co ${ }^{\mathrm{II}} \mathrm{M} 2 \mathrm{P}$ complex and coordination geometry around $\mathrm{Co}^{2+}$ in the $\mathrm{Co} / \mathrm{M} 2 \mathrm{P}$ precursor based on EXAFS data and the structure of $\mathrm{Co}(\mathrm{M} 2 \mathrm{P})\left(\mathrm{NH}_{3}\right)_{4} \mathrm{Cl}$ [99]. The $\mathrm{O}$ atoms coordinated to the $\mathrm{Co}$ atom could be water or hydroxyl ligands. (c) and (d) Co-M2P chains observed in two $\mathrm{Co}^{\mathrm{II}} \mathrm{M} 2 \mathrm{P}$ network structures [69]. In (c) the axial $\mathrm{O}$ atom on the Co is part of an M2P ligand in a neighboring Co-M2P chain. This structure features 5-coordinated Co which is not supported by the XAS data of the $\mathrm{Co} / \mathrm{M} 2 \mathrm{P}$ precursor. 


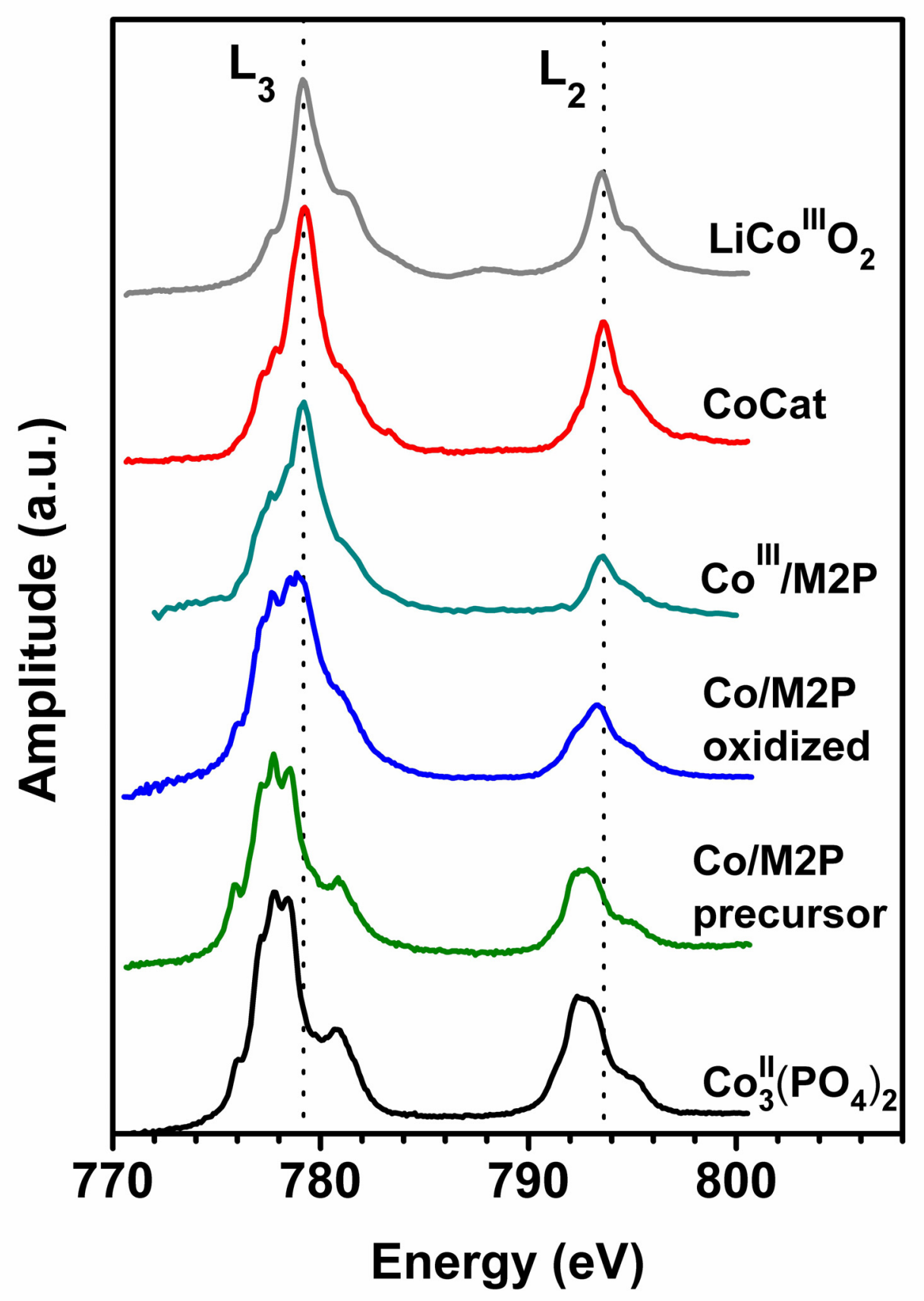

Figure 4. $\mathrm{Co} L$-edge spectra. From top to bottom: $\mathrm{LiCo}^{\mathrm{III}} \mathrm{O}_{2}$, CoCat, calculated $\mathrm{Co}{ }^{\mathrm{III}} / \mathrm{M} 2 \mathrm{P}$ spectrum, $\mathrm{Co} / \mathrm{M} 2 \mathrm{P}$ light-oxidized (experimental spectrum), $\mathrm{Co} / \mathrm{M} 2 \mathrm{P}$ precursor, $\mathrm{Co}{ }^{\mathrm{II}} \mathrm{O}$. The calculated spectrum was obtained by subtracting the experimental spectrum of the Co/M2P precursor from the spectrum of the light-oxidized $\mathrm{Co} / \mathrm{M} 2 \mathrm{P}$ sample (further detail is provided in the text). The dotted lines indicate the positions of the $L_{2}$ - and $L_{3}$-edges of $\mathrm{Co}^{\mathrm{III}}$ and thus help to identify a shift of these positions for $\mathrm{Co}^{\mathrm{II}}$ ions. 


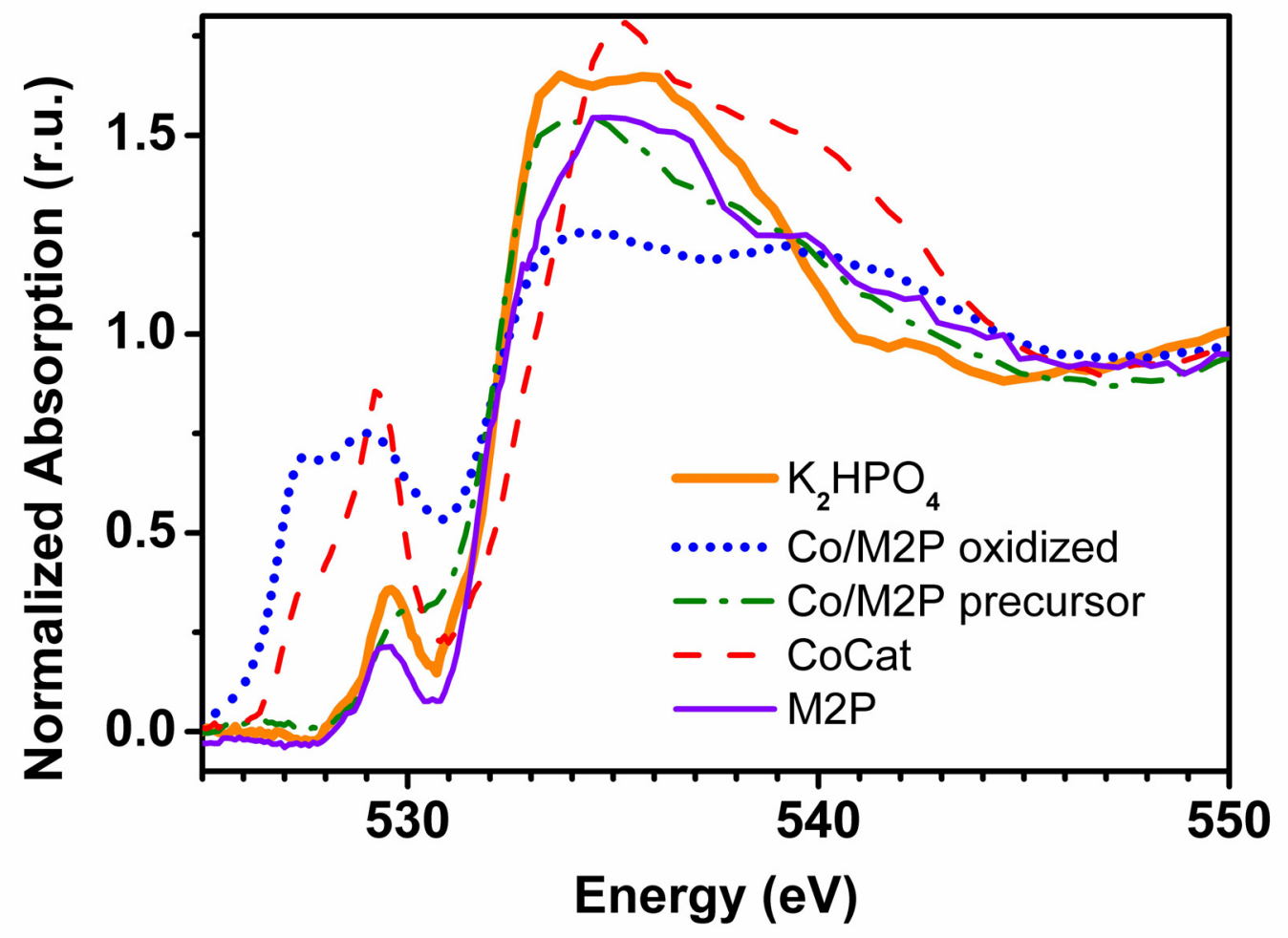

Figure 5. XANES spectra measured at the oxygen $K$-edge. The spectrum of the M2P ligand is compared to the spectrum of the $\mathrm{K}_{2} \mathrm{HPO}_{4}$ reference and to the spectrum of the $\mathrm{Co} / \mathrm{M} 2 \mathrm{P}$ precursor and Co/M2P after light oxidation. The oxygen $K$-edge spectrum of the electrodeposited CoCat is also shown. 


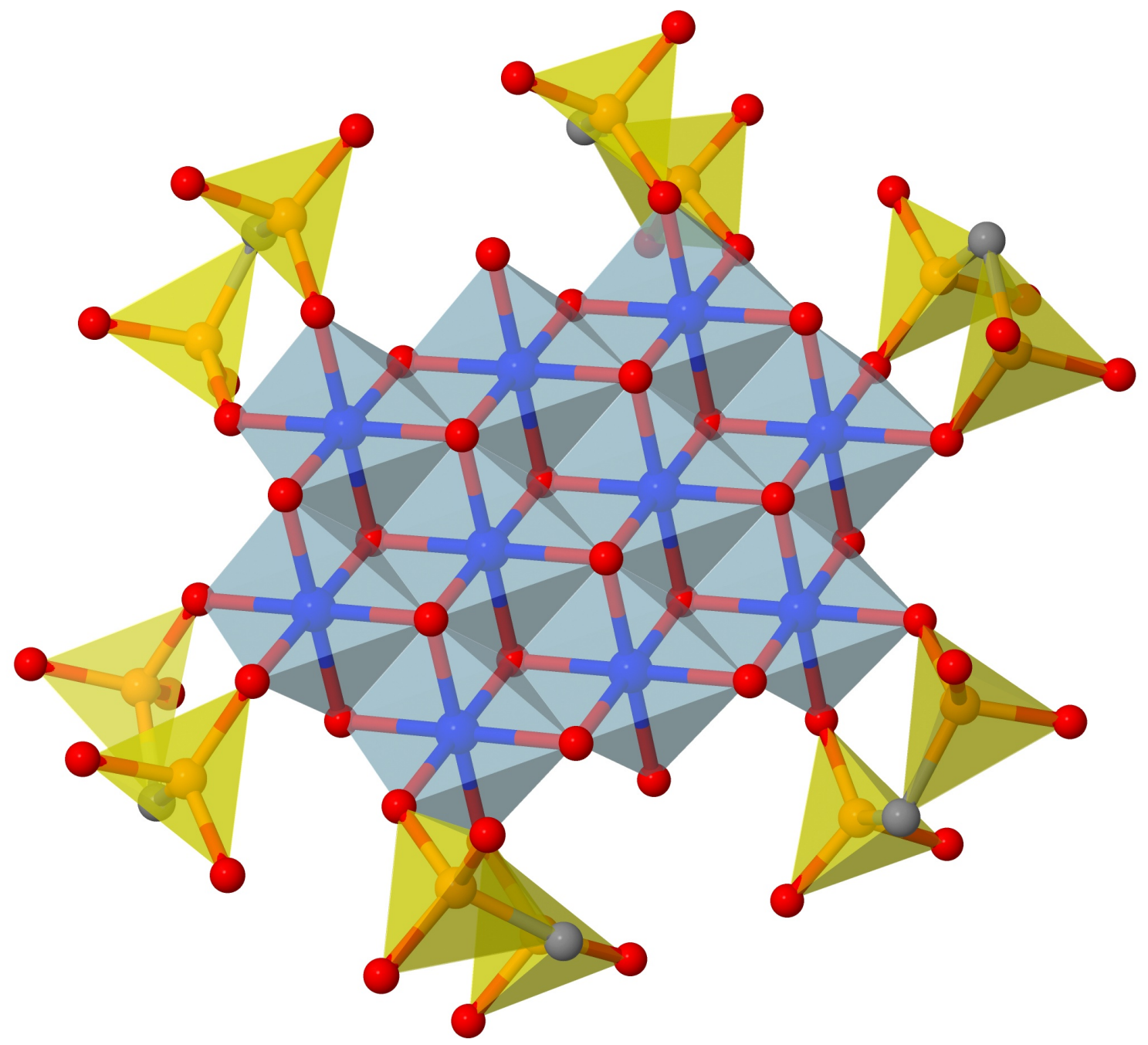

Figure 6. Possible structural motif deduced from XAS data for a $\mathrm{Co} / \mathrm{M} 2 \mathrm{P}$ nanoparticle as obtained by light-oxidation of $\mathrm{Co} / \mathrm{M} 2 \mathrm{P}$ precursor complexes $\left(\mathrm{CoO}_{6}\right.$ are presented as octahedra and $\mathrm{M} 2 \mathrm{P}$ ligands are presented as dimmers of $\mathrm{PO}_{3}$ tetrahedra interconnected by a carbon atom). 
Tables

Table 1. Simulation results of cobalt K-edge EXAFS ${ }^{\mathrm{a}}$

\begin{tabular}{|c|c|c|c|c|c|c|}
\hline & \multicolumn{2}{|c|}{$\begin{array}{l}\text { CoM2P } \\
\text { precursor } \\
\text { (darkness) }\end{array}$} & \multicolumn{2}{|l|}{$\begin{array}{l}\text { CoM2P } \\
\text { oxidized } \\
\text { (light) }\end{array}$} & \multicolumn{2}{|l|}{ CoCat } \\
\hline & $\mathbf{R}(\AA \AA)$ & $\mathbf{N}$ & $\mathbf{R}(\AA)$ & $\mathbf{N}$ & $\mathbf{R}(\AA)$ & $\mathbf{N}$ \\
\hline $\mathrm{Co}-\mathrm{O}$ & $2.1 \pm 0.01$ & $6.1 \pm 0.5$ & $1.90 \pm 0.01$ & $5.8 \pm 0.3$ & $1.89 \pm 0.01$ & $5.9 \pm 0.2$ \\
\hline $\mathrm{Co}-\mathrm{Co}$ & $\mathrm{n} / \mathrm{a}$ & $\mathrm{n} / \mathrm{a}$ & $2.81 \pm 0.01$ & $3.5 \pm 0.2$ & $2.80 \pm 0.01$ & $3.4 \pm 0.2$ \\
\hline Co-P & $3.4 \pm 0.04$ & $1.6 \pm 0.9$ & $3.6 \pm 0.04$ & $1.2 \pm 0.8$ & $\mathrm{n} / \mathrm{a}$ & $\mathrm{n} / \mathrm{a}$ \\
\hline $\mathrm{Co}-\mathrm{Co}$ & $\mathrm{n} / \mathrm{a}$ & $\mathrm{n} / \mathrm{a}$ & $5.6 \pm 0.02$ & $1.1 \pm 0.5$ & $5.62 \pm 0.04$ & $0.5 \pm 0.3$ \\
\hline
\end{tabular}




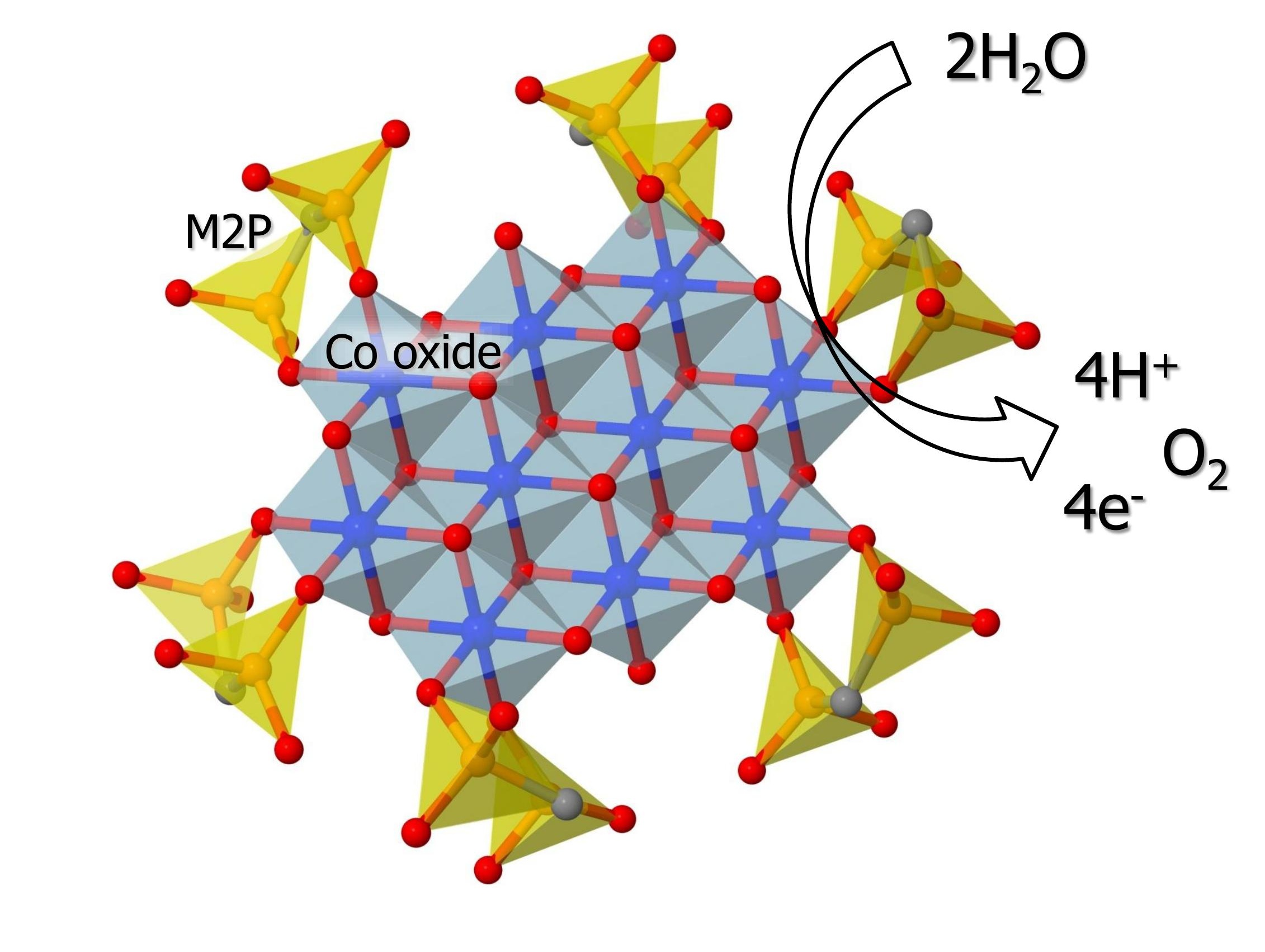

\section{.}

.

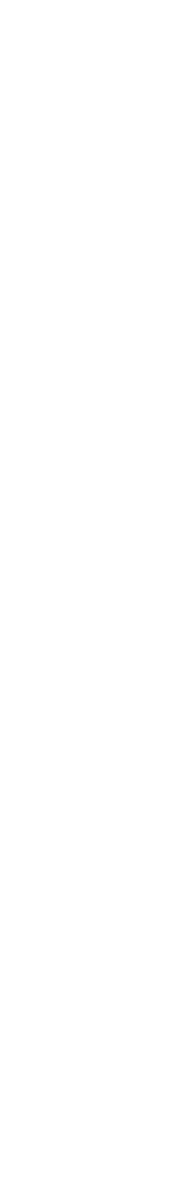


- atomic structure of water-oxidizing Co oxide/methylenediphosphonate nanoparticles by X-ray absorption spectroscopy

methylenediphosphonate prevents particle agglomeration during the catalytic reaction

water is oxidized and oxygen is produced in a process directly driven by light system shows prospects for direct linking of a photosensitizer 